\title{
Ear diseases pattern and hearing impairment in the Eastern Nepal- A study in a combined eye and ear set
}

up

\author{
Sanjeev Kumar Thakur', Sanjay Kumar Singh², Bindeshwar Mahato ${ }^{3}$, Anand Singh ${ }^{4}$ \\ ${ }^{1}$ ENT Consultant, Biratnagar Eye Hospital, Biratnagar-17, Nepal, ${ }^{2}$ Ophthalmology Consultant, Biratnagar Eye Hospital, Biratnagar-17, Nepal, \\ ${ }^{3}$ Hospital Manager, Biratnagar Eye Hospital, Biratnagar-17, Nepal, ${ }^{4}$ Eye-Ear Assistant, Biratnagar Eye Hospital, Biratnagar-17, Nepal
}

Background: This is a prevalence study of ear diseases and hearing impairment done in a combined eye and ear set up of Biratnagar Eye Hospital. This study was conducted in the Sunsari and Morang districts of Nepal. Its aim is to find out the ear disease and hearing impairment prevalent in the community. Materials and Methods: A total of 2259 people who visited eye camps were screened for ear diseases. Patients were examined by the eye and ear assistants under supervision of otolaryngologist. A head mirror, an otoscope, an aural syringe, kidney trays and light source and a set of tuning forks ( 512 and $256 \mathrm{~Hz}$ ) were used to assess the ear diseases and hearing loss. Results: A total of 1094 patients presented with ear diseases. Males were more than females [608(55.42\%) vs. 486(44.57\%)]. Children up to and below 15 years were $386(35.28 \%)$. The frequency of ear diseases were as follows: Impacted wax- $319(29.15 \%)$, chronic suppurative otitis media mucosal type - 307(28.06\%), otomycosis - 66 (6.03\%), furunculosis/otitis externa - 46 (4.29\%), Acute suppurative otitis media - 46 (4.2\%), tubal catarrhal - 34(3.1\%), otitis media with effusion - $24(2.19 \%)$, perichondritis - 21(1.91\%), Unsafe otitis media - 14(1.27\%), Foreign body in the ear $-4(0.36 \%)$ cases, Postraumatic perforation of tympanic membrane $-2(0.18 \%)$, deaf and mute - 12 (1.09\%). presbyacusis and other sensorineural hearing loss- 199(18.19\%). The point prevalence of otitis media was $17.3 \%$ (391) people. Hearing impairment was $64.99 \%$ (635 out of 977 patients above 5 years). Conclusion: Ear diseases and hearing impairment are very common in Sunsari and Morang districts of Nepal demanding immediate treatment.

Key words: Hearing impairment, Ear diseases, Combined eye and ear setup, Eastern Nepal

\section{INTRODUCTION}

360 million people worldwide have disabling hearing loss and $50 \%$ of them are preventable. This is approximately $5.3 \%$ of the world population. 32 million of these are children of less than 15 years. ${ }^{1}$ The World Health Organization has indicated that a prevalence rate of chronic suppurative otitis media greater than $4 \%$ in a defined population of children is indicative of a massive public health problem requiring urgent attention. ${ }^{2}$

Chronic suppurative otitis media (CSOM) is one of the most common ear diseases in South East Asia having a prevalence of approximately, $5.2 \%$ in the general population. ${ }^{3}$ Nepal is a landlocked developing country and has been listed as one of the least developed nations by United Nations. ${ }^{4}$ It is ridden with illiteracy, poverty and sociopolitical problem. It has very poor medical system with lack of manpower, medicine, instruments and facilities. ${ }^{5} 2011$ (2068) census shows the hearing disability to be $15.45 \%$ out of $1.94 \%$ total disability in the Nepalese population. $1.48 \%$ suffers with a combined hearing loss and vision impairment. Speech problem was seen in $11.5 \%{ }^{6}$

In 1991, BRINOS/TUTH reported $16.6 \%$ hearing loss in general Nepalese population. Thirty-two percent of 
hearing impairment was associated with otitis media, which was more common in children. ${ }^{7}$ A study carried out by BP Koirala institute of health sciences in Sunsari district of Eastern part of Nepal showed a prevalence of otitis media in 10.3\% among those surveyed in health examination camp. ${ }^{8}$ A community oriented study was conducted in Eastern Nepal to find out the awareness in population about the ear disease, its impact on personal and socioeconomic life. The result showed the management of ear diseases to be very poor. ${ }^{9}$

The associated hearing loss due to otitis media has a life-long impact as it occurs during speech and language development and the early school years. ${ }^{10} \mathrm{~A}$ recent study in Nigeria has concluded that hearing loss due to chronic suppurative otitis media had an adverse effect on the academic performance of the children. ${ }^{11}$

Most of the ENT surgeons (nearly 75\%) are in capital. In the Eastern part of Nepal, the availability of ENT surgeon with surgical facility in government institution is very less. Private set up is not easy to afford for most of the people. In addition most of the people live in rural areas and are not aware of the consequences of ear disease. So the available facility is also not utilized to its maximum. Hence there is a need for community oriented ear care programme that would go up to the door of these sufferers and manage their ailments. In 2001, in rural areas of western Nepal, community ear assistants and volunteers were found to be very effective for ear care delivery. ${ }^{12}$ Also in New Delhi, India in 2010, Dr. Shroff's charity eye hospital evaluated integration of eye and ear care at primary level and found it to be very effective. ${ }^{13}$

In view of above background, in January 2012, as a pilot project, Biratnagar Eye Hospital (combined eye and ear programme) took an initiative for setting up of community oriented primary ear and hearing care services in conjunction with existing eye setup to address the ear care needs of underprivileged and marginalized section of the Eastern Nepalese society to achieve the mission as outlined in SOUND HEARING 2030. ${ }^{14}$

\section{Aims and objectives}

To assess the ear diseases and hearing impairment prevalent in the Sunsari and Morang districts of Eastern Nepal with the help of eye and ear assistants of Biratnagar Eye Hospital in a combined eye and ear setup.

\section{MATERIALS AND METHODS}

This pilot project was a cross-sectional study conducted on a total of 2259 people in the year 2012. Eye Camps in the district of Sunsari and Morang were organized at various remote areas all throughout the year. Together with the eye camp, 45 ear camps were also organized. The set up for eye camp was utilized. Those patients who complained of hearing loss and ear problems were examined by the eye and ear assistants under supervision of consultant otolaryngologist. Three eye care workers were trained for 3 months at Tribhuwan university teaching hospital, Kathmandu and oriented for detection of ear diseases and use of tuning fork to screen hearing loss. They were equipped with a head mirror, an Otoscope, a set of tuning forks, an aural syringe, kidney trays and light source. After detailed history and Physical examination, hearing loss was assessed by tuning fork. The Weber and the Rinne's test were performed with the 512 and $256 \mathrm{~Hz}$ tuning fork. These tests were done before syringing and other procedures as WHO criteria. Appropriate primary management was advised at community level. Syringing was done for cases of ear wax. Health education regarding awareness of ear diseases, aural hygiene and ear care precautions was given. Appropriate referrals for further assessment, surgical and rehabilitative management to the needy was done. The importance of improved and hygienic living conditions, nutrition, immunization, ear cleaning and avoidance of water entry in the ear was emphasized.

The results were tabulated and statistical analysis was done in frequency and percentage.

\section{RESULTS}

1094 people (including 386 children up to 15 years), with definite ear ailments and hearing loss were identified (Table 1).

Males 608(55.42\%) were more common than females $486(44.57 \%)$. Point prevalence of otitis media was found

\begin{tabular}{lcccc}
$\begin{array}{l}\text { Table 1: Otoscopic findings of patients with ear } \\
\text { problems }\end{array}$ & Male & Female & Total & Percentage \\
\hline Diagnosis & 13 & 21 & 34 & 3.10 \\
\hline Tubal catarrhal & 15 & 9 & 24 & 2.19 \\
Ome & 26 & 20 & 46 & 4.20 \\
Asom & 173 & 134 & 307 & 28.06 \\
Csomtt & 8 & 6 & 14 & 1.27 \\
Csomaa & 30 & 16 & 46 & 4.20 \\
Furunculosis/otitis externa & 7 & 14 & 21 & 1.91 \\
Perichondritis & 179 & 140 & 319 & 29.15 \\
Impacted wax & 28 & 38 & 66 & 6.03 \\
Otomycosis & 3 & 1 & 4 & 0.36 \\
Foreign body ear & 1 & 1 & 2 & 0.18 \\
Traumatic perforation & 117 & 82 & 199 & 18.19 \\
Presbyacusis, ?Snhl & 8 & 4 & 12 & 1.09 \\
Deaf/mutism & 608 & 486 & 1094 & 100 \\
Total & 55.57 & 44.42 & 100 & \\
Percentage & & & & \\
\hline
\end{tabular}


in $17.3 \%(391)$. One hundred seventy-three (44.24\%) of these were children with otitis media. The commonest pathology found was impacted wax in 319 (29.15\%) followed by chronic suppurative otitis media mucosal type in $307(28.06 \%)$ patients. Unsafe otitis media was found in $14(1.27 \%)$ only. Acute suppurative otitis media in $46(4.2 \%)$, otitis media with effusion in $24(2.19 \%)$ and tubal catarrhal in 34(3.1\%) were other pathologies found. Various infections like otomycosis in 66 (6.03\%), furunculosis/otitis externa in $46(4.29 \%)$ and perichondritis in $21(1.91 \%)$ patients were seen in the community. Foreign body in the ear was found in $4(0.36 \%)$ cases. Postraumatic perforation of tympanic membrane was found in $2(0.18 \%)$ patients. Twelve $(1.09 \%)$ children and adults were found to be deaf and mute. Age related hearing loss-presbyacusis and other sensorineural hearing loss- suspected was found in $199(18.19 \%)$ of those attending the camps and most were elderly who needed hearing aids.

Three hundred eight-six (35.28\%) of those affected were children up to and below 15 years (Table 2). On analyzing them separately, the commonest pathology was impacted wax in 156 (40.41\%). Chronic suppurative otitis media, mucosal was found in $117(30.31 \%)$. The frequency of acute suppurative otitis media was in $35(9.06 \%)$ and otitis media with effusion was found to be in 16(4.14\%). Unsafe otitis media was found in $5(1.29 \%)$ children complaining of continuous and foul smelling discharge from the ear. Otomycosis was seen in 11 (2.84\%) children. Various other infections like furunculosis/otitis externa in 23(5.95\%) and perichondritis in $9(2.33 \%)$ was seen. Suspected congenital hearing loss was found in $7(1.81 \%)$ children. Post traumatic perforation was seen in $1(0.25 \%)$.

The hearing analysis was done using tuning fork $512 \mathrm{~Hz}$ and hearing loss was recorded in $64.99 \%$ (635 out of 977 patients

\begin{tabular}{|c|c|c|c|c|c|c|}
\hline \multirow{2}{*}{$\begin{array}{l}\text { Diagnosis of } \\
\text { upto } 15 \text { years }\end{array}$} & \multicolumn{2}{|c|}{$0-5$ years } & \multicolumn{2}{|c|}{$>5-15$ years } & \multirow[t]{2}{*}{ Total } & \multirow[t]{2}{*}{ Percentage } \\
\hline & M & $F$ & $M$ & $F$ & & \\
\hline Tubal catarrh & & & 2 & 3 & 5 & 1.29 \\
\hline Ome & 4 & 3 & 6 & 3 & 16 & 4.14 \\
\hline Asom & 10 & 9 & 9 & 7 & 35 & 9.06 \\
\hline Csomtt & 7 & 9 & 54 & 47 & 117 & 30.31 \\
\hline Csomaa & & & 3 & 2 & 5 & 1.29 \\
\hline $\begin{array}{l}\text { Furunculosis/ } \\
\text { otitis externa }\end{array}$ & 3 & 4 & 11 & 5 & 23 & 5.95 \\
\hline Perichondritis & & 1 & 2 & 6 & 9 & 2.33 \\
\hline Impacted wax & 34 & 28 & 60 & 34 & 156 & 40.41 \\
\hline Foreign body & 1 & & & & 1 & 0.25 \\
\hline $\begin{array}{l}\text { Posttraumatic } \\
\text { perforation }\end{array}$ & & & & 1 & 1 & 0.25 \\
\hline Deaf/mutism & 2 & & 3 & 2 & 7 & 1.81 \\
\hline Otomycosis & 1 & 1 & 3 & 6 & 11 & 2.84 \\
\hline Total & 62 & 55 & 153 & 116 & 386 & 100 \\
\hline
\end{tabular}

above 5 years who could understand the instructions). However use of audiometer would have helped in quantifying the degree and classifying the type of hearing loss.

A total of 211 cases $(19.28 \%$ ) of suspected Sensorineural hearing loss (age related and other causes) were identified.

\section{DISCUSSION}

Utilization of eye set up for ear care was a new experience. WHO promotes combining eye and ear services for tackling the problem of hearing loss. ${ }^{2} \mathrm{WHO}$ together with CBM and other NGO's have launched the program of Sound Hearing 2030 for South East Asia with aim of reducing the prevalence of hearing loss with the philosophy of combining eye and ear services. ${ }^{14}$ Similar program was done by Shroff's Eye hospital in Daryaganj, New Delhi and they found that combining eye and ear services were very effective. ${ }^{13}$

The commonest disease found was impacted wax, as a whole both in all age groups included and in those below and equal to 15 years. The high incidence is similar to the findings as in the studies done in Nepal and Nigeria. ${ }^{15-19}$

Chronic suppurative otitis media was the next commonest disease in both the groups. Acute suppurative otitis media and otitis media with effusion were also common, more in the children of 15 years and below. The other studies conducted in Nepal also showed the similar results. ${ }^{7-9,15,18,19}$ Most of the studies done in Nepal has shown chronic otitis media to be very common in the population screened. ${ }^{9,12,15}$

Overall, in this survey, point prevalence of otitis media was found in $17.3 \%(391) .173$ (44.24\%) of these were children of 15 years and below. Zakzouk and al-Muhaimeed also showed similar high incidence of otitis media in their study(19.6\%). ${ }^{20} \mathrm{~A}$ cross-sectional, clinical and epidemiological study in Kolkata and Hooghly revealed middle ear pathology to be more common in rural area $(20 \%)$ compared to $(12.6 \%)$ in urban areas. ${ }^{21}$ Amin et al found chronic otitis media to be $18.46 \%$ to $35.58 \%$ in four rural ENT camps done in Bangladesh..$^{22}$ Other studies in Eastern Nepal have documented a prevalence of otitis media ranging from $10.3 \%$ to $13.2 \%{ }^{8,15,23}$. Contrary to these studies, a relatively low incidence was observed by Kalpana and Chamyal $(4.75 \%) .{ }^{24} \mathrm{~A}$ relatively high incidence of otitis media in our study could be because we had targeted those interior most rural areas where proper treatment was not available, similar to the study in rural areas by Bandyopadhyay et al and Amin et al..$^{21,22}$

The problem of hearing impairment and ear pathologies was more common in lower socioeconomic group, in the 
study done by Upadhyay and Maharjan. ${ }^{8,15}$ Poor nutrition, incomplete immunization and unhygienic living conditions could be responsible for this susceptibility to otitis media and various ear infections of these children. ${ }^{8,9,15}$ The habit of bathing in ponds and not following the precautions to avoid water entry like use of cotton and cream or ear plugs in cases of infection of ears could be the cause for recurring and persisiting ear discharge. Warm and humid weather, scratching of ears with sticks, twigs, metal or pencils might lead to these different infections in the ears like otomycosis, otitis externa, furunculosis and perichondritis. ${ }^{8,9,15}$

In 1991, BRINOS/TUTH reported $16.6 \%$ hearing loss in general Nepalese population. Thirty-two percent of hearing impairment was associated with otitis media, which was more common in children. ${ }^{5}$

Our study revealed hearing loss in $64.99 \%$ of the study population. Upadhyay also showed hearing loss in $65.33 \%$ of their study population. ' However even mild hearing loss was taken in to consideration in our study as well as in study by Upadhyay. However we had not used audiometer and only tuning fork was used to screen the hearing loss.

Our study has shown prevalence of presbyacusis and suspected sensorineural hearing loss to be $18.19 \%$. The prevalence of hearing impairment in adult population in southern Taiwan in a study was $21.4 \% .{ }^{25}$ However, in a Korean study where subjects aged 65 years and above was screened, the incidence of presbyacusis was $37.8 \%$ and $8.3 \%$ for $\geq 27 \mathrm{~dB}$ HL criterion and $\geq 41 \mathrm{~dB}$ HL criterion, respectively. ${ }^{26}$

Lack of manpower and resources can adversely affect the treatment and prevention of hearing impairment. It would take years to train the manpower and build a separate infrastructure. However, by the use of existing infrastructure and resources, as in this study, we can train the existing eye care workers who are already involved in managing the patients. They can be trained to detect hearing loss and ear diseases. They can also provide primary treatment. Appropriate referrals can be made for the needy. As the awareness regarding existence and impact of hearing loss and ear diseases is poor in the community, health education about early detection and prevention of hearing impairment can be given. ${ }^{8,915}$ This model could be helpful in reducing prevalence of hearing impairment early and in a cost effective manner as outlined by the goals of Sound Hearing 2030. ${ }^{14}$

\section{CONCLUSION}

Ear diseases and hearing impairment are very common in Sunsari and Morang districts of Nepal demanding immediate treatment.

\section{Limitation and further scope of the study}

This is a pilot study. Random sampling technique was not performed. With this data, further large population of Sunsari and Morang districts can be taken to find out the exact prevalence of ear diseases and hearing impairment. Only tuning fork was used to assess the hearing impairment. Further detailed objective assessment of hearing impairment and ear diseases in the community should be done. Further detailed studies should be done to find out the feasibility of an integrated eye and ear care program.

\section{REFERENCES}

1. Mortality and Burden of Diseases, WHO; 2011 Estimates for disabling hearing loss (DHL). http://www.who.int/mediacentre/ factsheets/fs300/en/, http://www.who.int/pbd/deafness/news/ Millionslivewithhearingloss.pdf

2. WHO/CIBA Foundation Workshop. Prevention of hearing impairment from chronic otitis media. WHO/PDH/98.4. 1996. London, CIBA Foundation. 19-11-1996

3. Prevention and causes of deafness and hearing impairment in the South East Asia Region. State of Hearing and Ear care in the South East Asia Region. WHO Regional Office for SE Asia, 2004:9-10

4. http://www.unohrlls.org/en/ldc/25.

5. Nepal Population Report 2011 Published by: Government of Nepal Ministry of Health and Population, Population Division Ramshahpath, Kathmandu, Nepal. www.mohp.gov.np

6. National Population and Housing Census 2011(National Report) Government of Nepal. National Planning Commission Secretariat, Central Bureau of Statistics Kathmandu, Nepal. November, 2012. Vol 1(1,4).

7. Survey on prevalence of deafness and ear diseases. Tribhuvan university teaching hospital and British Nepal Otology Society.-1991.

8. Upadhyay MP. Sunsari health examination survey, BPKIHS, 1996.

9. Upadhyay S, Jha AK and Mishra SC. Community oriented research program for prevention of deafness with special stress on children- a preliminary report. Indian journal of otolaryngology and head and neck surgery 2004; 56(4):262-265.

10. Coates HL, Morris PS, Leach AJ and Couzos S. Otitis media in Aboriginal children: Tackling a major health problem. MJA 2002; 177:177-178.

11. Olatoke F, Ologe FE, Nwawolo CC and Saka MJ. The prevalence of hearing loss among schoolchildren with chronic suppurative otitis media in Nigeria, and its effect on academic performance. Ear Nose Throat J 2008; 87:E19.

12. Shrestha R, Baral $K$ and Neil W. Community ear care delivery by community ear assistants and volunteers: A pilot study. J Laryngol Otol 2001; 115: 869-873.

13. Integrating eye and ear care at primary level- evaluation of primary ear and hearing care project of Dr, shroff's charity eye hospital, New Delhi, India.

14. http://www.soundhearing2030.org.

15. Maharjan M, Bhandari S, Singh S and Mishra SC. Prevalence of otitis media in school going children in eastern Nepal. Kathmandu university medical journal 2006; 4(4): 479-482.

16. JAE Eziyi, YB Amusa, CC Nwawolo and BC Ezeanolue. Wax Impaction in Nigerian School Children. East and Central African Journal of Surgery 2011; 16: 40-45. 
17. Olusanya BO, Okolo AA and ljaduola GT. The hearing profile of Nigerian school children. Int J Pediatr Otorhinolaryngol 2000; 55:173-179.

18. Adhikari P. Pattern of ear diseases in rural school children: Experiences of free health camps in Nepal. Int J Otorhinolaryngol 2009; 73:1278-1280.

19. Adhikari P, Kharel DB, Ma J, Baral DR, Pandey T, Rijal R et al. Pattern of otological diseases in school going children of Kathmandu valley. Arq Int Otorrinolaringol 2008; 12:502-505.

20. Zakzouk SM, al-Muhaimeed HS: Hearing impairment among "at risk' children. Int J Pediatr Otorhinolaryngol 1997; 11; 39:255.

21. Bandyopadhyay R, Sengupta A, Dasgupta A, Biswas R, Mukherjee $S$ and Biswas $A B$. A comparative study of common ear morbidity pattern among the primary school children of an urban slum of Kolkata and rural area of Hooghly. J Indian Med Assoc 2005; 103:428, 430-432.
22. Amin MN, Chowdhury WA, Sheikh MS and Abdullah M. Pattern of ENT diseases in rural Bangladesh. J Bangladesh Coll Phys Surg 1985; 7:23-27.

23. Mishra SC, Shah PK and Kandpal N. Hearing retardation amongst school age Bhutanese refugees. Indian J Otolaryngol 2002; 8: 5-8.

24. Kalpana R and Chamyal PC. Study of prevalence and etiology of the hearing loss amongst school going children. Indian $\mathrm{J}$ Otolaryngol \& HNS 1997; 49:142-144.

25. Lin CY, Yang YC, Guo YL, Wu CH, Chang CJ and Wu JL. Prevalence of hearing impairment in an adult population in Southern Taiwan. Int J Audiol 2007; 732-737.

26. Kim H N, Kim S G, Lee HK, Ohrr H, Moon S K, 2000. Incidence of presbycusis of Korean populations in Seoul, Kyunggi and Kangwon provinces. J. Korean. Med. Sci. 15, 580-584.

\section{Authors Contribution:}

Thakur SK - designed and conducted the study, tabulated and analysed the data, drafted and reviewed the manuscript; Singh SK - Contributed to the study design and reviewed the manuscript; Mahato B - Contributed to the study design and reviewed the manuscript; Singh A - Contributed to the conduction and tabulation of the study.

Source of Support: Nil, Conflict of Interest: None declared. 